\title{
Using social network analysis to assess the Pontocaspian biodiversity conservation capacity in Ukraine
}

\author{
$\underline{\text { Aleksandre Gogaladze }}^{1,2}, \underline{\text { Frank P. Wesselingh }}^{1}, \underline{\text { Koos Biesmeijer }}^{1,2}$, Vitaliy V. Anistratenko $^{3}, \underline{\text { Natalia Gozak }}^{4}, \underline{\text { Mikhail O. Son }}^{5}$ \\ and Niels Raes ${ }^{1,6}$
}

\begin{abstract}
Social networks, defined as sets of relationships between stakeholder organizations, are important determinants of constructive actions for biodiversity conservation. Such actions are achieved through cooperation between various stakeholders, exchange of information, and joint planning and implementation. We used a mix of qualitative and quantitative social network analysis methods to investigate the interorganizational network of stakeholders in Ukraine, and the implications of network properties for the conservation of Pontocaspian biodiversity. Pontocaspian biota contains unique and endemic fauna, which are threatened by anthropogenic impacts; this makes effective conservation measures an urgent priority. We identified a well-connected, centralized network in Ukraine. However, the strong network has not resulted in effective conservation of Pontocaspian biodiversity. Suboptimal conservation action stems from the subordinate role of Pontocaspian species in the interorganizational interactions, likely due to lack of knowledge regarding Pontocaspian taxa. Social variables, such as funding scarcity and legal constraints, further limit the effectiveness of biodiversity conservation actions. We conclude that the current landscape of stakeholders in Ukraine is well placed to rapidly improve conservation actions if they are supplied with improved information and recognition of conservation needs of Pontocaspian taxa, combined with improved financial and legal conditions.
\end{abstract}

Key Words: biodiversity; effective conservation; information exchange; Pontocaspian region; social network analysis; Ukraine

\section{INTRODUCTION}

Pontocaspian biota comprises endemic flora and fauna which evolved in the isolated anomalohaline (brackish) lake systems in and around the Black and Caspian Sea basins over the past two million years (Kostianoy and Kosarev 2005, Krijgsman et al. 2019). This biota includes mollusks, crustaceans, and fish, as well as planktonic groups such as dinoflagellates and diatoms (Grigorovich et al. 2003, Marret et al. 2004). Within their native range, the diversity and abundance of Pontocaspian species are subject to anthropogenic pressures, such as habitat destruction, introduction of invasive alien species, and pollution (Grinevetsky et al. 2016, Lattuada et al. 2019, van de Velde et al. 2019). The Ukrainian territory covers an important part of Pontocaspian habitats (Fig. 1). In Ukraine, Pontocaspian species richness and abundance are in decline and require effective conservation actions (Bloesch et al. 2006, Anistratenko and Anistratenko 2018, Wesselingh et al. 2019). Legal instruments for the conservation of Pontocaspian biota are confined to a few taxa (Dumont et al. 1999, Anistratenko 2009, Munasypova-Motyash 2009a, b), and scientific information regarding most Pontocaspian species is scarce and restricted to individual stakeholder organizations (ECODIT LLC 2017).

This study is part of the Horizon 2020 "Pontocaspian Biodiversity Rise and Demise" (PRIDE) program. The PRIDE program was designed to generate scientific knowledge on Pontocaspian biodiversity, inform decision-making, and guide effective conservation policy. Effective collaboration between stakeholder organizations, defined as high levels of information exchange and coordination of joint actions, is essential for adequate implementation of biodiversity conservation measures (Binning et al. 1999, Briggs 2001, Durham et al. 2014). Different types of
Fig. 1. Study area. Black stars represent the stakeholder institutions (IDs in Table 1). Green areas indicate major Pontocaspian habitats.

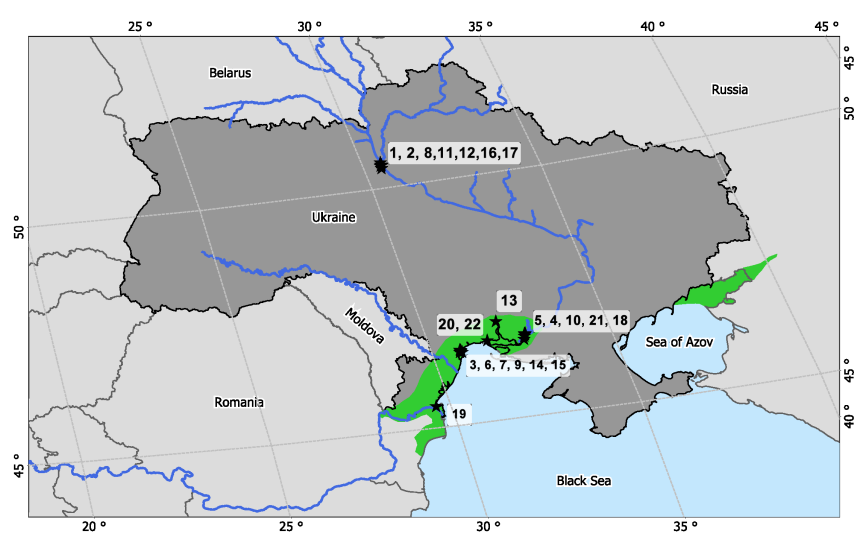

stakeholders such as academic organizations, policy-makers, nongovernmental organizations, and public sector and conservation managers need to be involved and act at different levels of biodiversity conservation. This involvement ranges from the delivery of scientific information to the enforcement of rules and regulations and actual implementation of conservation measures (Durham et al. 2014). Scientific information, knowledge, and management experiences are at the heart of these processes (Lee 1999, Salafsky et al. 2002). Therefore, effective

\footnotetext{
${ }^{1}$ Naturalis Biodiversity Center, ${ }^{2}$ Institute of Environmental Sciences (CML), Leiden University, ${ }^{3}$ Schmalhausen Institute of Zoology, Department of Invertebrate Fauna and Systematics, National Academy of Sciences of Ukraine, ${ }^{4}$ NGO "Ecoaction", ${ }^{5}$ Institute of Marine Biology, National Academy of Sciences of Ukraine, ${ }^{6}$ NLBIF - Netherlands Biodiversity Information Facility
} 
collaboration to address environmental issues depends largely on knowledge sharing and implementation in conservation policy (Pullin and Knight 2001, Cash et al. 2003, Francis and Goodman 2010). Recent studies indicate that defining and understanding the different types and roles of stakeholders and their professional relationships - including the exchange of information-are a requirement for optimal conservation planning and the protection of biological diversity (Isaac 2012, Mills et al. 2014, Paletto et al. 2015).

A commonly used tool to analyze and visualize relationships between stakeholders is a social network analysis (SNA), which models the statistical properties of a social network (Wasserman and Faust 1994). Social networks define the relationships between stakeholder organizations by capturing the scale of information and knowledge sharing, as well as joint actions and decisionmaking between network members (Ernoul and Wardell-Johnson 2013, Barnes et al. 2016). Social networks are therefore critical to facilitate biodiversity conservation and effective management of natural resources (Bodin et al. 2006, Bodin and Crona 2009). Empirical studies on the relationships between the structural characteristics of a network and the outcomes for biodiversity conservation identify which properties of a network are beneficial for conservation. For example, well-connected networks allow for the effective exchange of information and facilitate the definition and prioritization of biodiversity conservation challenges (Weimann 1982, Abrahamson and Rosenkopf 1997, Sandström and Carlsson 2008). Decision-making is facilitated when one or a few institutions take a central position in a network (Leavitt 1951). Furthermore, bidirectional knowledge and information exchange between producers and users is positively correlated with increased social and environmental impacts of scientific research (Fazey et al. 2013). Similarly, strong connections and frequent interactions among stakeholders are indicative of high levels of trust, and are necessary to communicate complex biodiversity-related information (Newman and Dale 2005, Crona and Bodin 2006). In summary, a structurally strong network that enables effective exchange of information between different types of stakeholders has the potential to enhance collaboration and achieve optimal conservation of biodiversity.

High levels of information sharing alone, however, may not suffice because networks may exist in which not all actors hold shared ideas and goals, which makes its functioning less effective (Mizruchi and Galaskiewicz 1993, Ernstson et al. 2008). Additionally, power relations among stakeholder organizations are important determinants of network outcomes (Markovsky et al. 1988). Different stakeholders have different interests and power, potentially resulting in more powerful actors using their favorable positions to their own advantage (Adger et al. 2005). Moreover, social variables such as funding schemes and funding availability, governance arrangements, stability and functioning of organizations, personal attitudes, and willingness to collaborate further influence the functioning of the network (Knoke and Kuklinski 1991, Cowling and Wilhelm-Rechmann 2007, Fuhse and Mützel 2011). The extent to which the exchanged information in an existing network influences conservation policy depends on its content, relevance, and legitimacy (Stringer and Dougill 2013, Reed et al. 2014). Often, the information and scientific knowledge shared with policy-makers is difficult to interpret or may be contested depending on how knowledge is produced, translated, or transformed as it is shared (Reed et al.
2013, Stringer and Dougill 2013). According to Prell et al. (2009), Reed et al. (2009), and Hauck et al. (2015), the combination of SNA methods and the qualitative analysis of stakeholders' knowledge, referred to as the mixed-methods approach, allows for triangulation between the network structure, social variables, and their outcomes for conservation action. The mixed-method is an adequate approach to link the structure of the social relationships expressed in the network to individual stakeholders and the context in which the relations exist (Fuhse and Mützel 2011, Herz et al. 2015).

We combine the results of SNA with qualitative analysis of stakeholder knowledge to understand the structure and functioning of the network and the outcomes of network properties for the conservation of Pontocaspian biota. We aim to (a) quantify the Pontocaspian biodiversity-related informationsharing network using SNA, (b) examine the content of the network interactions using a qualitative approach, (c) identify social variables that influence collaboration, and (d) outline areas for improvement for effective conservation of Pontocaspian biodiversity in Ukraine.

\section{METHODS}

\section{Stakeholder identification and prioritization}

Twenty-nine stakeholder institutions directly or indirectly involved in Pontocaspian biodiversity research and conservation were identified through online research and exploratory consultations with PRIDE partner institutions in Ukraine for inclusion in the study. We define a stakeholder as a person or group who influences or is influenced by Pontocaspian biodiversity-related research, following Durham et al. (2014). Stakeholder roles were assessed through online inquiries of their activities and subsequent interviews. Stakeholders that lacked any activities or interest in Pontocaspian biodiversity were subsequently omitted from the study, which resulted in a final list of 22 institutions (Table 1, Fig. 1). These institutions were assigned to four stakeholder categories based on their function and responsibilities: academic (Acad), governmental (Gov), nongovernmental (NGO), and protected areas $(\mathrm{Pa})$.

\section{Data collection}

A questionnaire and semistructured, indepth interviews with the heads or vice-heads of institutions were used to acquire quantitative and qualitative network data (Appendix 1). Interviews of 1-3 hours were conducted between May and July 2017. A "whole network analysis" approach was employed, in which a standardized questionnaire was used to question each stakeholder about each of the other 21 stakeholders. All interviews were audio recorded.

\section{Qualitative data}

Data on the content of interactions among stakeholder organizations were collected using two qualitative questions that first asked the interviewees to describe their professional relationships with the other stakeholders, and that second specifically asked whether the interaction involved Pontocaspian biodiversity (see Appendix 1 for the full interview protocol). If the interaction did not involve Pontocaspian biodiversity, the protocol was to move on asking about the next stakeholder from the list of stakeholders (Table 1). If the interaction involved Pontocaspian biodiversity-related topics, the interviewees were asked to rank the strength of reported interaction using a table 
Table 1. Stakeholders included in the study, and their respective stakeholder categories. "Acad" - academic institutions, "Gov" governmental, "NGO" - nongovernmental, and "Pa" - protected areas.

\begin{tabular}{|c|c|c|c|c|}
\hline ID & Abbreviation & Category & Organization name & Department/Service \\
\hline 1 & IZAN & Acad & $\begin{array}{l}\text { I.I. Schmalhausen Institute of Zoology of the } \\
\text { National Academy of Sciences of Ukraine (NASU) }\end{array}$ & $\begin{array}{l}\text { Department of Invertebrate Fauna and } \\
\text { Systematics }\end{array}$ \\
\hline 2 & IHB & Acad & Institute of Hydrobiology of the NASU & \\
\hline 3 & IMB & Acad & Institute of Marine Biology of the NASU & \\
\hline 4 & KHS & Acad & Kherson Hydrobiology Station of the NASU & \\
\hline 5 & KSU & Acad & Kherson State University & Faculty of Biology, Geography, and Ecology \\
\hline 6 & ONU & Acad & Odessa National University & Faculty of Biology \\
\hline 7 & YN & Acad & $\begin{array}{l}\text { Southern Scientific Research Institute of Marine } \\
\text { Fisheries and Oceanography }\end{array}$ & \\
\hline 8 & $\mathrm{KNU}$ & Acad & Taras Shevchenko National University of Kiev & Department of Ecology and Zoology \\
\hline 9 & US & Acad & Ukrainian Scientific Center of Ecology of the Sea & \\
\hline 10 & KSRA & Gov & Kherson State Regional Administration & Department of Ecology \\
\hline 11 & MAPF & Gov & Ministry of Agrarian Policy and Food & Department of Agriculture \\
\hline 12 & MENR & Gov & $\begin{array}{l}\text { Ministry of Ecology and Natural Resources of } \\
\text { Ukraine }\end{array}$ & $\begin{array}{l}\text { Department for Protection of Natural } \\
\text { Resources }\end{array}$ \\
\hline 13 & MSRA & Gov & Mykolaiv State Regional Administration & Department of Ecology \\
\hline 14 & OSRA & Gov & Odessa State Regional Administration & Department of Ecology \\
\hline 15 & CRS & NGO & Center for Regional Studies & \\
\hline 16 & NECU & NGO & National Ecological Centre of Ukraine & \\
\hline 17 & WWF & NGO & World Wide Fund for Nature in Ukraine & \\
\hline 18 & BSBR & $\mathrm{Pa}$ & Black Sea Biosphere Reserve of the NASU & \\
\hline 19 & DBR & $\mathrm{Pa}$ & Danube Biosphere Reserve of the NASU & \\
\hline 20 & KSRP & $\mathrm{Pa}$ & Kinburn Spit Regional Landscape Park & \\
\hline 21 & LDNP & $\mathrm{Pa}$ & Lower Dnieper National Nature Park & \\
\hline 22 & NPBS & $\mathrm{Pa}$ & National Park "Biloberezhia Sviatoslava" & \\
\hline
\end{tabular}

of strength definitions developed as part of the questionnaire (Table A1.1). Once a Pontocaspian biodiversity-related link was established, stakeholders were asked to report if the interaction was perceived to be sufficient or insufficient to achieve the desired level of collaboration and information exchange. Not all stakeholder institutions were easily reached or willing to answer the interview questions, which resulted in some missing data. We used the imputation-by-reconstruction method (Stork and Richards 1992) to deal with missing data (see Appendix 2 for details).

\section{Ouantitative data}

We used the frequency of contact as a measure of strength (weight) of relational links, following Prell et al. (2009), Paletto et al. (2015), and Giurca and Metz (2018). Five weight categories ( 0 to 4$)$ were used, ranging from no contact (0) to very frequent contact (4). We defined strong relationships as the weights greater than or equal to 3 . Only formal connections were considered in the network because the informal, personal contacts could not be confirmed. The values given to the strength of confirmed relationships between pairs of stakeholders did not always match. In the cases of bidirectional information exchange, tie values were left as reported by the stakeholders. In the case of unidirectional information transfer, however, the lowest tie value was selected. Answers to this question allowed for the generation of a weighted, directed, information and knowledge transfer network.

\section{Analysis}

\section{Qualitative analysis}

For qualitative data analysis, we used the established methods of Ryan and Bernard (2003) and Bradley et al. (2007), and applied an inductive approach. This means that the themes of interaction were determined based on acquired data and not on theoretical knowledge or assumptions. Transcribed interviews were carefully examined and read multiple times to understand the context of the network. The themes in the transcribed text were identified based on repetitions (Bogdan and Taylor 1975). A "constant comparison" method was used to refine the dimensions of determined themes and to identify new themes (Glaser et al. 1967). The identified themes for both the content of confirmed relational links and perceived sufficiency of relationships were counted, and their relative importance was determined based on the order of frequency. Identified themes of interaction were grouped in three categories based on similarity: "communication relations"linkages between actors used primarily for transmitting information; "collaboration relations"- the ties between actors consisting of joint action; and "authority/power relations"relational links, which indicate the rights of organizations to issue commands and obligations of other organizations to obey.

\section{Social network analysis}

For readability, we provide all SNA term definitions in Appendix 3. Basic network characteristics, such as number of actors and relational ties, graph density, and network centralization index, were calculated using the CRAN R package "igraph" (Csardi and Nepusz 2006), which was also used to visualize the sociogram. Mean shortest distance, a measure of average distance between actors in the network, was calculated using the CRAN R package "tnet" (Opsahl 2009) because the "igraph" package does not take edge weights into account when measuring the shortest distance. The network centralization index was calculated based on degree centrality scores of individual nodes. Measurements of density and centralization were converted to percentages for visual representation. 
Centrality of individual nodes was measured by the degree centrality and betweenness centrality measures (Freeman 1978). We regarded the central stakeholders as those with centrality scores greater than or equal to the third quartile threshold, following the methods of Grilli et al. (2015), Paletto et al. (2015), and Yamaki (2017).

Brokers were identified based on the combination of quantitative and qualitative data. Quantitatively, we regarded brokers to be the stakeholders with high betweenness scores, which also accounted for low Burt's constraint values. Qualitatively, we searched for evidence of brokerage from the network narratives, following the definition of Fazey et al. (2013), whereby brokerage implies involvement in the mobilization of information, deliberation between different types of stakeholders, and potentially, mediation through working groups to address conservation issues. We used only strong ties $(\geq 3)$ to identify brokers because they reflect regular contact.

Finally, we used a null-model approach to examine the degree of "homophily" in the network (Newman 2003). We tested whether densities within and between stakeholder groups (defined by the stakeholder category) were significantly higher or lower than random expectation. We randomly assigned nodes to the stakeholders proportional to the true network and subsequently assessed the stakeholders within and between group densities. This was replicated 1000 times, and the resulting 1000 stakeholder group density values were ranked from low to high. Observed within and between group densities were then compared to the randomized results. If the actual density values were outside the $95 \%$ confidence interval of the random distribution, we regarded the true within or between group densities to be significantly higher (top $2.5 \%$ ) or lower (lower $2.5 \%$ ) than expected by random chance.

\section{RESULTS}

In total, $82 \%$ of the network data was gathered, with 18 of 22 institutions interviewed (16 face-to-face and two by an electronic questionnaire). Three of the four remaining institutions were formally contacted but did not respond and did not complete the electronic questionnaire. One institution could not be reached during the fieldwork period.

\section{Network structure}

The quantitative results revealed a well-connected informationsharing network with a total number of 191 confirmed directed relational ties out of 462 potential ties, resulting in a network edge density of $41 \%$ (Table 2). The Pontocaspian biodiversity conservation network was centralized on a few central stakeholders (degree of centralization $=38 \%$ ), and none of the stakeholders occupied an isolated position in the network (Fig. 2). On average, each organization had 17 relational ties (including both incoming and outgoing ties). Most of the informationsharing links were strong $(61 \%$; weight $\geq 3)$, reflecting regular contacts (Table 2). The mean distance between any two actors was 1.5 . In-degree and out-degree were very closely correlated (rho $=0.78)$, meaning that the exchange of information was reciprocated; i.e., stakeholders that were sending information to many institutions were also receiving information from multiple sources.
Table 2. Network statistics

\begin{tabular}{lc}
\hline \hline Network data & Values \\
\hline Total no. actors & 22 \\
Total no. ties & 191 \\
Mean degree & 17 \\
Density (\%) & 41 \\
Degree of centralization (\%) & 38 \\
Tie reciprocity (rho) & 0.78 \\
Strong/weak ties (\%) & $61 / 39$ \\
Mean shortest distance & 1.5 \\
\hline
\end{tabular}

Fig. 2. Sociogram of the information-transferring network of stakeholder organizations involved in Pontocaspian biodiversity conservation and planning. Nodes represent organizations (see Table 1 for full names). The size of the nodes corresponds to the node strength. Arrows represent relationships between the nodes and show the direction of relevant information transfer. Black arrows (ties with value $\geq 3$ ) represent strong relationships; gray arrows (ties with value $<3$ ) represent weak relationships.

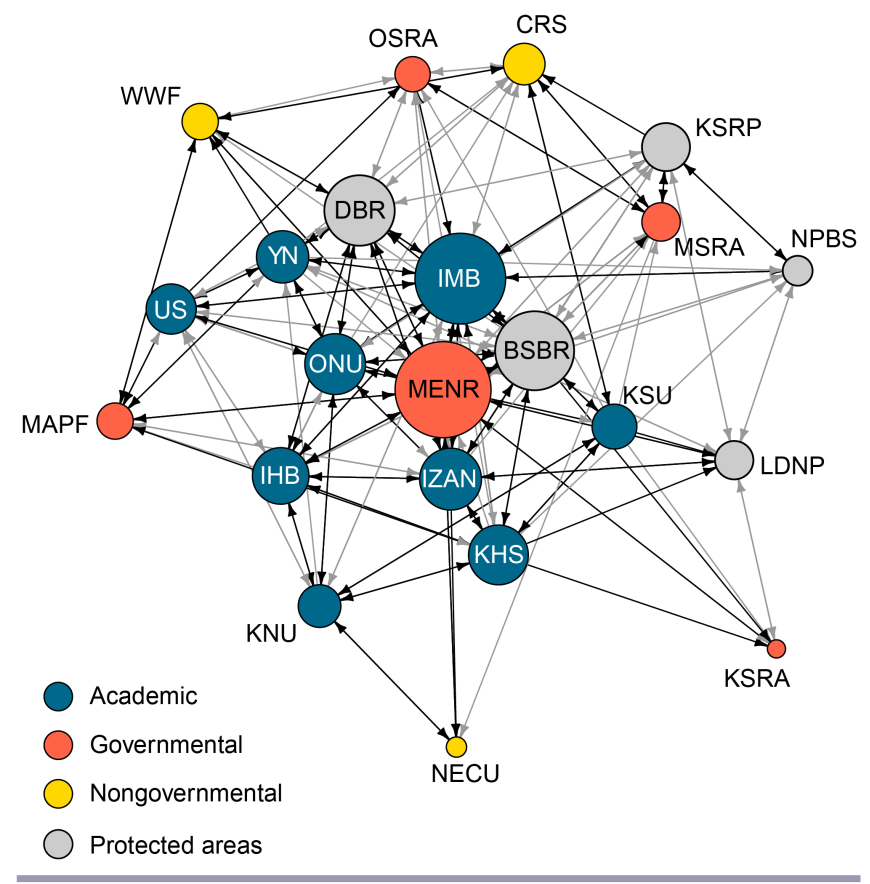

\section{Relational content}

From the network narratives, we identified 13 themes of stakeholder interactions (Fig. 3, Table A2.1). These interactions included "communication relations" - e.g., exchange of data and management experiences; "collaboration relations"-e.g., joint research and conservation planning; and "power relations"-e. g., directing action and scientific supervision. Most stakeholders indicated that they have multiple kinds of interactions with other stakeholders (Table A2.2). For example, organizations that were collaborating in joint conservation projects also exchanged ecological and environmental information, as well as opinions. 
Similarly, organizations that were involved in commercial fishing exchanged information regarding living water resources, and shared management experiences (Table A2.2). Few stakeholders engaged only in the exchange of information and did not collaborate with each other. For example, Kherson Hydrobiology Station regularly reported to the Ministry of Ecology and to the regional administrations on study results but did not engage with them in joint actions. Similarly, protected areas exchanged information and opinions among each other but hardly collaborated with each other. Of the identified 191 relational links, 67 had a single theme of interaction, 72 had two themes of interaction, 43 had three themes of interaction, eight had four themes of interaction, and one had five themes of interaction. The links with more relational content were significantly stronger than links with less relational content $(p<0.001)$ (Fig. A2.1).

Fig. 3. Categories and themes of stakeholder interactions. Values in pie charts represent the absolute number of times the themes were mentioned by stakeholders. See definition of themes in Table A2.1.

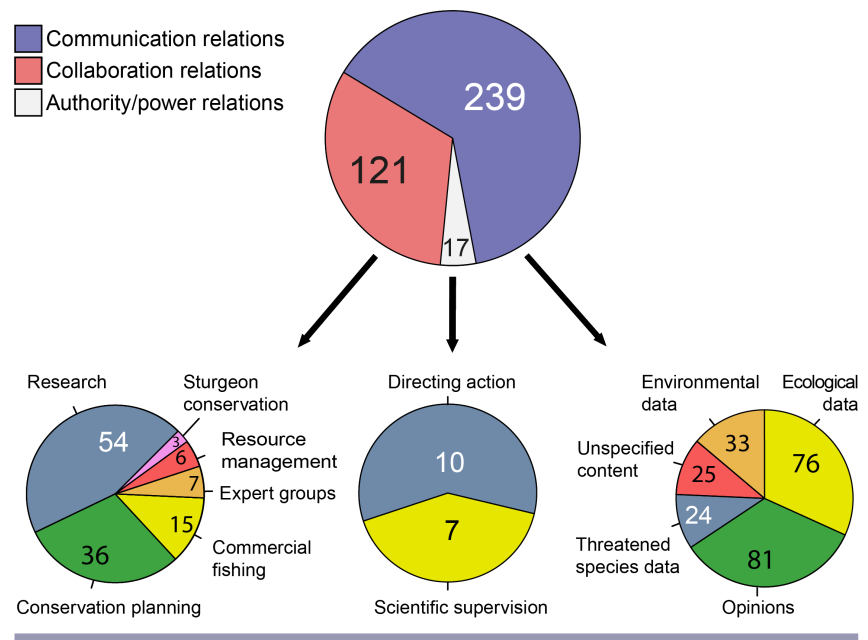

Only one theme, namely "Sturgeon conservation", was identified as directly targeting the Pontocaspian species. Interviewees mentioned this theme three times (Fig. 3, Table A2.1). The other themes did not directly address Pontocaspian biodiversity, but Pontocaspian species were incidental to the interactions. For example, shared data on ecosystem functioning and dynamics (theme "Ecological data"), assessments of water parameters (theme "Environmental data"), advice on restoration projects (theme "conservation planning"), and joint fieldwork and research (theme "Research") were reported by the interviewees to occasionally involve Pontocaspian habitats and/or species. We did not include a standard question on the definition of Pontocaspian species in our questionnaire, but the network narratives indicated that stakeholders had slightly different ideas on what Pontocaspian species and habitats comprise. In some cases, interviewees avoided specifying in which context Pontocaspian biodiversity-related data were exchanged (Fig. 3, Table A2.1, collated within the theme "Unspecified content").

\section{Perceived sufficiency of interactions}

A total of 42 relational links (31\% of 137 links for which the sufficiency was indicated by interviewees) were reported to be insufficient; i.e., below the desired intensity of collaboration and information exchange (Table A2.3). Insufficient collaboration was attributed mostly to "budget constraints" (18 times) and "legal limitations" (15 times). "Budget constraints" referred to either a general lack of funding or unfavorable funding schemes, which restricted the participation of stakeholders in a project. "Legal limitations" referred to inconsistency in conservation policy, which resulted from contradictions in national laws. "Lack of interconnection" and "employee turnover" were minor factors limiting collaboration (Table A2.3). Interestingly, most of the "insufficient" relational links were strong links ("budget constraints"-13 strong versus five weak, and "legal limitations" - eight strong versus seven weak links), which suggests that regular stakeholder contacts within the network were not necessarily indicative of sufficient collaboration.

\section{Stakeholder centrality and brokerage}

Node-level statistics identified central stakeholders (Table 3). Three of nine academic institutions had a very high number of relational ties ("degree centrality" score higher than or equal to the third quartile threshold $\geq 20$ ). The Ministry of Ecology had the most connections in the network and was the only governmental organization with a high degree centrality score. None of the NGOs accounted for high degree centrality values. The Black Sea Biosphere Reserve and the Danube Biosphere Reserve represented two of the five protected areas with high connectivity. The ratio of strong to weak ties (for individual stakeholders) was diverse throughout the network. All central stakeholders had more strong ties than weak ties.

We identified four organizations with structurally favorable positions to act as brokers in the network, displayed through their high betweenness centrality (higher than or equal to the third quartile threshold $\geq 20$ ) and low Burt's constraint values (lower than or equal to the first quartile threshold $\leq 27)$. These organizations were the Ministry of Ecology, the Institute of Marine Biology, the Black Sea Biosphere Reserve, and the Kherson Hydrobiology Station (Table 3). However, qualitative data showed that only the Ministry of Ecology and the Institute of Marine Biology were actually involved in brokering behavior, such as mobilization of information and resources, deliberation between different types of stakeholders, and coordination of research and conservation action (Table A2.2, themes "Expert groups", "Scientific supervision", and "Directing action"). For example, the Ministry of Ecology was reported to form expert groups composed of representatives of various stakeholder categories to discuss progress toward the implementation of the national conservation agenda and to facilitate strategic planning (theme "Expert groups"). Furthermore, the Ministry of Ecology was involved in directing and coordinating the actions of several scientific institutions (e.g., the Ukrainian Scientific Center of Ecology of the Sea) and all the protected areas (theme "Directing action"). The Institute of Marine Biology was a scientific supervisor for several protected areas (e.g., the Danube Biosphere Reserve, the Kinburn Spit Regional Landscape Park, and the National Park "Biloberezhia Sviatoslava") and acted as a bridge between them, which were otherwise disconnected or weakly connected (Table A2.4, "Pa-Pa"-10 weak links).

The Black Sea Biosphere Reserve and Kherson Hydrobiology Station, although structurally well positioned, did not take 
Table 3. Node-specific measures. Values between brackets under "Degree centrality" represent the in-degree and out-degree measures, respectively. In bold are values higher than or equal to the third quartile threshold (lower than or equal to the first quartile threshold in case of "Burt's constraint"). Numbers between brackets under "Qualitative data" represent the frequency of respective themes characterizing the incoming and outgoing ties.

\begin{tabular}{|c|c|c|c|c|c|c|c|}
\hline \multirow[b]{2}{*}{ Abbr. } & \multicolumn{4}{|c|}{ Quantitative data } & \multicolumn{3}{|c|}{ Qualitative data } \\
\hline & Degree centrality & $\begin{array}{c}\text { No. ties strong/ } \\
\text { weak }\end{array}$ & $\begin{array}{c}\text { Betweenness } \\
\text { centrality }\end{array}$ & $\begin{array}{c}\text { Burt's } \\
\text { constraint } \\
\end{array}$ & $\begin{array}{c}\text { Communication } \\
\text { relations }\end{array}$ & $\begin{array}{c}\text { Collaboration } \\
\text { relations }\end{array}$ & $\begin{array}{c}\text { Authority/power } \\
\text { relations }\end{array}$ \\
\hline MENR & $32(17,15)$ & $20 / 12$ & 110 & 16 & $47(30,17)$ & $18(12,6)$ & $6(0,6)$ \\
\hline IMB & $28(14,14)$ & $23 / 5$ & 108 & 21 & $48(20,28)$ & $16(8,8)$ & $4(0,4)$ \\
\hline BSBR & $28(13,15)$ & $17 / 11$ & 46 & 25 & $38(18,20)$ & $14(7,7)$ & $2(2,0)$ \\
\hline $\mathrm{DBR}^{\dagger}$ & $24(12,12)$ & $16 / 8$ & 16 & 28 & $31(13,18)$ & $20(9,11)$ & $3(3,0)$ \\
\hline IZAN & $21(9,12)$ & $14 / 7$ & 12 & 28 & $21(10,11)$ & $13(5,8)$ & $1(0,1)$ \\
\hline ONU & $21(10,11)$ & $14 / 7$ & 12 & 28 & $21(9,12)$ & $15(10,5)$ & 0 \\
\hline IHB & $19(9,10)$ & $14 / 5$ & 7 & 29 & $28(9,19)$ & $15(6,9)$ & $1(0,1)$ \\
\hline KHS & $19(7,12)$ & $14 / 5$ & 20 & 26 & $24(7,17)$ & $13(6,7)$ & $1(1,0)$ \\
\hline $\mathrm{YN}$ & $19(8,11)$ & $10 / 9$ & 5 & 34 & $33(11,22)$ & $18(8,10)$ & $1(1,0)$ \\
\hline US & $19(9,10)$ & $9 / 10$ & 7 & 36 & $20(7,13)$ & $13(6,7)$ & $2(2,0)$ \\
\hline KSRP & $18(9,9)$ & $7 / 11$ & 12 & 42 & $23(9,14)$ & $7(3,4)$ & $3(3,0)$ \\
\hline $\mathrm{KNU}^{\dagger}$ & $15(7,8)$ & $10 / 5$ & 10 & 29 & $15(7,8)$ & $8(4,4)$ & 0 \\
\hline $\mathrm{CRS}^{\dagger}$ & $15(9,6)$ & $7 / 8$ & 18 & 33 & $22(14,8)$ & $6(3,3)$ & 0 \\
\hline KSU & $14(5,9)$ & $10 / 4$ & 20 & 28 & $6(5,1)$ & $11(3,8)$ & $1(0,1)$ \\
\hline $\mathrm{OSRA}^{\dagger}$ & $14(9,5)$ & $5 / 9$ & 1 & 42 & $16(14,2)$ & $9(5,4)$ & $1(0,1)$ \\
\hline LDNP & $14(8,6)$ & $6 / 8$ & 3 & 33 & $13(8,5)$ & $8(4,4)$ & $2(2,0)$ \\
\hline MAPF & $13(7,6)$ & $7 / 6$ & 4 & 36 & $12(8,4)$ & $10(7,3)$ & $1(0,1)$ \\
\hline MSRA & $13(7,6)$ & $8 / 5$ & 15 & 27 & $19(12,7)$ & $6(3,3)$ & $2(1,1)$ \\
\hline NPBS & $12(7,5)$ & $4 / 8$ & 0 & 69 & $17(10,7)$ & $4(2,2)$ & $2(2,0)$ \\
\hline WWF & $11(6,5)$ & $9 / 2$ & 20 & 31 & $9(6,3)$ & $12(5,7)$ & 0 \\
\hline KSRA & $7(5,2)$ & $3 / 4$ & 0 & 44 & $8(7,1)$ & $3(3,0)$ & $1(0,1)$ \\
\hline NECU & $6(4,2)$ & $5 / 1$ & 7 & 38 & $7(5,2)$ & $3(2,1)$ & 0 \\
\hline
\end{tabular}

${ }^{\dagger}$ Institutions that could not be interviewed for which relationships were imputed

advantage of this to initiate Pontocaspian biodiversity-related conservation action. These organizations were hosting academic institutions and protected area representatives to do research on their territories, and reported the study results to the regional administrations (Table A2.2), which resulted in their many, and potentially bridging, ties (Table 3 ). However, there was no evidence that these organizations use their favorable positions to initiate any collective action with regard to Pontocaspian biodiversity conservation, perhaps due to the low priority for Pontocaspian species conservation and lack of funding.

\section{Stakeholder group connectivity}

Academic institutions had significantly higher within-group density value than expected by random chance (Table A2.4). They were also strongly connected to each other ( 35 strong versus 12 weak connections), indicative of regular contact. When in contact, the academic organizations exchanged data and experiences, and engaged in face-to-face interactions such as joint research and conservation planning. Links among academic organizations were constrained mostly by lack of necessary funding for research and collaboration (Table A2.4). Lack of funding also limited cooperation between the academic sector and protected areas because the academic institutions could not afford regular fieldwork within protected areas. Academic institutions and nongovernmental organizations were significantly less connected with each other than expected by chance, thereby reflecting comparatively little exchange of information and collaboration between these groups. When in contact, academic institutions and NGOs rarely met face-to-face, and interacted mostly via "Communication relations"(Table A2.4). For example, the Center for Regional Studies was found to be requesting and receiving scientific information from the Institute of Marine Biology, Odessa National University, Kherson State University, and the Southern Scientific Research Institute of Marine Fisheries and Oceanography on a yearly or biannual basis, but no collaborative relation was found between them. The Center for Regional Studies used the requested information for preparing reports on the state of the environment and for providing consultancy to the central, regional, and local authorities. Besides the lack of funding, unfavorable policy regulations impeded the desired levels of collaboration between academic organizations and other stakeholder categories. For example, Odessa National University and the Southern Scientific Research Institute of Marine Fisheries and Oceanography reported having difficulty conducting an inventory of aquatic species within the protected areas due to a disagreement between the Ministry of Agrarian Policy and the Ministry of Ecology on common study methodology. Policy regulations also obstructed collaboration efforts between NGOs and the protected areas, and among governmental organizations (Table A2.4).

Most stakeholder groups had considerably more "Communication relations" than "Collaboration relations"(Table A2.4), which may indicate that the exchanged information did not always result in conservation action in Ukraine. Governmental organizations were the only ones with an equal amount of information exchange and collaborative action. However, governmental organizations were collaborating among themselves only on topics related to commercial fishing and management of aquatic resources but not on topics related to joint conservation planning (Table A2.4). 
Some stakeholders were involved in specific interactions. For example, the World Wildlife Fund (WWF) in Ukraine was a beneficiary in the project "Life for Danube Sturgeons", which focuses on saving the sturgeon species. To implement the project, WWF collaborated with the governmental organizations, such as the Ministry of Ecology and the Ministry of Agrarian Policy, and a single protected area, namely the Danube Delta Biosphere Reserve (Table A2.2).

\section{DISCUSSION}

Pontocaspian biodiversity is in need of effective conservation action, which requires the coordinated involvement of institutions, including governmental organizations, NGOs, the academic sector, and protected areas. In our analysis, we found that the Pontocaspian conservation network in Ukraine has structural properties capable of allowing optimal conservation action. Institutions within the network are well connected (high network density) and tend to have strong connections to many partners with whom they collaborate and regularly exchange information (Tables 2 and 3, Fig. 2). The two most central stakeholders in the network, such as the Ministry of Ecology and the Institute of Marine Biology, exploit their structurally favorable positions and act as brokers by mobilizing information and resources and deliberating between different types of stakeholders (Tables 3 and A2.2). These are, according to network theory, characteristics of a well-functioning network (Leavitt 1951, Crona and Bodin 2006, Fazey et al. 2013). Yet, from our interview results and recently published studies, it is evident that the conservation status of Pontocaspian biota in Ukraine is suboptimal (Dumont et al. 1999, Anistratenko and Anistratenko 2018, Wesselingh et al. 2019). This is caused primarily by the fact that Pontocaspian biodiversity does not drive the interorganizational interactions in Ukraine (Fig. 3, Table A2.1). Instead, the primary focus is on the conservation of the flagship species, notably sturgeons, which results in most Pontocaspian taxa being absent from the conservation agenda. The general lack of knowledge on Pontocaspian species identities and ecology (with the exception of sturgeons) is a likely cause of their observed subordinate role in the organizational interactions. Furthermore, the optimal functioning of the structurally adequate network for biodiversity conservation is challenged by social variables such as limited funding availability and lack of consistency in conservation policy.

\section{Network relations and challenges to optimal Pontocaspian biodiversity conservation}

Stakeholder organizations in Ukraine are in close contact but rarely discuss or act on issues related to Pontocaspian species (Fig. 3, Table A2.1). Typically, stakeholder interactions target Pontocaspian flagship species, such as sturgeons; commercially important species, including few Pontocaspian species such as the gobies; and alien invasive species (Fig. 3, Table A2.1, themes "Sturgeon conservation", "Commercial fishing", and "Ecological data"). Few other Pontocaspian species, such as some bivalve species, were mentioned as part of the theme "Threatened species data" (Fig. 3, Table A2.1). Themes listed under the "Collaboration relations" category mostly exclude Pontocaspian species, with the exception of sturgeons. However, these themes do target Pontocaspian habitats, including coastal areas and the lower stretches of the rivers (Fig. 1), thereby indirectly affecting biological communities that occupy these habitats. The minor role of Pontocaspian species in organizational interactions is likely a result of a low level of knowledge regarding Pontocaspian species, including a lack of clarity on species identities. Recent research on Pontocaspian mollusk taxonomy and autecology supports this observation by showing that many of the Pontocaspian mollusk species have disputed identities and multiple synonymies, and are data deficient in the IUCN Red List databases (Wesselingh et al. 2019).

In addition to knowledge gaps, use of exchanged information in conservation planning is suboptimal and needs to be studied further. From the interviews, we learned that information exchange between the academic sector and governmental organizations and between protected areas and governmental organizations occurs on mandatory bases. However, the advice and recommendations that are exchanged are not always taken into consideration and do not always translate into conservation action, even when stakeholders are strongly interlinked (Table A2.4). Additionally, we found that regional administrations, central governmental bodies, the academic sector, and NGOs operate at a variety of scales and sometimes independently, which complicates conservation efforts. For example, the regional administrations involved in biodiversity conservation were separated from the Ministry of Ecology in 2010. As a result, the actions of the regional administrations are no longer centrally coordinated and controlled-reported as "Legal limitations" among "Gov-Gov" interactions (Table A2.4). Regional administrations are not decision-makers but execute with disparate views on biodiversity conservation targets. Effective biodiversity management and species conservation requires coordinated actions from different institutions to be based on the best available knowledge and recommendations (Binning et al. 1999, Briggs 2001).

Optimal functioning of the studied network is restricted by funding availability (Tables A2.3 and A2.4). Project-based collaboration on conservation of Pontocaspian biodiversity is limited in Ukraine (Fig. 3, Table A2.1), and the exchange of information occurs mostly due to organizational mandates or voluntary actions and supporting attitudes of organizations. Academic institutions suffer most from the lack of funding, which often translates into weak connections (Table A2.4). From the stakeholder narratives, we learned that weak connections rarely result from conflicting views or lack of acquaintance, but rather from lack of funding. For example, few academic organizations can financially afford to carry out fieldwork within protected areas more than once a year. Limited available funding to study the Pontocaspian species and their absence from the global biodiversity databases such as the IUCN Red List of Threatened Species reduces the interest of NGOs in collaborating on topics related to these taxa. Consequently, NGOs focus on obtaining funding on flagship species conservation and have a relatively marginal position in the network (Tables 3 and A2.4).

In some cases, the criteria for grant applications further limit access to funding for Pontocaspian biodiversity projects. For example, universities are excluded from projects funded by the National Academy of Sciences of Ukraine (NASU), and organizations under NASU are not eligible to take part in projects funded by the Ministry of Education and Science. Similarly, 
grants from regional administrations are aimed mostly at organizations within the region. International small grants are available mostly to NGOs or NGOs plus a regional administration. The European Union "LIFE Program" projects are aimed at organizations registered in the EU and usually involve one or a few institutions from Ukraine as associated beneficiaries; e.g., involvement of WWF in Ukraine in a sturgeon conservation project (Table A2.2). Cross-Border Cooperation projects are the only ones that frequently combine different types of stakeholder organizations, such as academic institutions, NGOs, and protected areas. While the term "Pontocaspian" is largely absent in the formulations of Cross-Border Cooperation projects, these projects target Pontocaspian habitats such as the lower Danube River and the Black Sea coastline. Cross-Border Cooperation grants, however, limit stakeholder participation to local or regional parties. For example, the programs on Black Sea conservation allow participation of only those organizations that are located in the Odessa, Kherson, and Mykolaiv regions. Similarly, grants on the conservation of the Danube Delta target only organizations from the Odessa region. In summary, available funding schemes in Ukraine limit the participation of multiple stakeholders from different administrative regions with unparalleled ecological knowledge and experiences to collaborate and act together, which is a necessary precondition for optimal conservation. This was previously recognized as a challenge for research and conservation action in Ukraine by an independent panel of experts and national peers, and recommendations have been developed for improvement through increased availability of grants to all types of stakeholder organizations from a centralized state fund (Chang et al. 2017).

The lack of consistency in biodiversity conservation policy ("Legal limitations") is another factor that hampers adequate collaboration and Pontocaspian conservation action (Tables A2.3 and A2.4). "Legal limitations" refer to uncoordinated action of regional administrations, and to some of the national laws in Ukraine that are contradictory and create confusion among conservation organizations. For example, fish and mollusks, as well as water resources in general are under the control of the Ministry of Agrarian Policy and Food (MAPF), whereas protected areas are under governance of the Ministry of Ecology. Laws made by MAPF that regulate research methodologies and set standards to assess commercial fish and mollusk species richness and population densities are not implemented by the Ministry of Ecology. Therefore, academic institutions contracted by MAPF face restrictions in conducting research within protected areas (Table A2.4). Interviewed stakeholders are aware of the contradicting national laws, and the Ministry of Ecology is taking a leading role in resolving the legal inconsistencies and coordinating efforts to reach better alignment of laws and regulations.

\section{A strong social network is in place to improve Pontocaspian conservation}

We argue that the key structural characteristics of the studied network, such as high number of connections and reciprocated ties, high network centralization, and clearly defined broker institutions, are favorable for effective biodiversity conservation actions (Tables 2 and 3). The content of interactions (Fig. 3, Table A2.1) and the social variables, such as the funding and policy frameworks (Table A2.3), seem to be more consequential for biodiversity conservation outcomes than the network structure itself. According to network theory, in the initial phase of the conservation process, centralized networks are highly beneficial for disseminating information, mobilizing and coordinating resources, and making simple decisions (Leavitt 1951, Olsson et al. 2004). Decentralized networks with multiple stakeholders holding many relational ties are more suitable for solving complex long-term conservation challenges (Leavitt 1951, Crona and Bodin 2006). In Ukraine, our results together with the reviewed literature suggest that there is a long tradition of research on Pontocaspian biodiversity, but the translation of research outputs into effective biodiversity conservation actions is relatively novel (Anistratenko 2009, Munasypova-Motyash 2009a, b, Cuttelod et al. 2011). A "centralized network" such as we find in the current phase is well placed to overcome this hurdle, which makes the existing network structurally suited to implementing an improvement in Pontocaspian biodiversity conservation actions.

The two identified broker organizations in the studied network (Table 3) are very important stakeholders; they considerably influence the functioning of the network, and need to be involved in long-term Pontocaspian biodiversity conservation and planning in Ukraine. Furthermore, the qualitative data indicate that the WWF in Ukraine is involved in the conservation of Pontocaspian flagship species, such as the sturgeons, through the enforcement of conservation laws and awareness-raising activities (Table A2.2). Besides the identified interactions in the studied network, the WWF in Ukraine operates a large network of young volunteers and students, and closely collaborates with different entities such as fishery patrol inspectors and state border guards in Odessa. Therefore, the WWF in Ukraine has the potential to rapidly spread new knowledge throughout the network and beyond, if it is supplied with information. The WWF in Ukraine, together with two identified broker institutions - the Ministry of Ecology and Institute of Marine Biology - can play a critical role in the initial phase of Pontocaspian biodiversity conservation action through organizational capacity building and awareness raising to expand the current scope of conservation initiatives beyond flagship species. However, the factors hampering conservation efforts must be addressed to create conditions in Ukraine that can support collective actions. In summary, the observed structural properties of the network suggest that improving the content of interactions by resolving taxonomic uncertainties and raising awareness of nonflagship species, combined with addressing limiting social variables, such as funding scarcity and contradicting laws, will enable a rapid improvement in the effectiveness of Pontocaspian biodiversity conservation actions.

\section{CONCLUSION}

We identified a strong stakeholder network for Pontocaspian biodiversity conservation in Ukraine. Yet, indications of Pontocaspian biodiversity decline have not resulted in strong, concerted conservation actions. Overall, it emerged that Pontocaspian taxa play a minor role in interorganizational interactions. Academic institutions and the protected areas study specific aspects of Pontocaspian biodiversity, but research outputs are not always related to, or translated into, environmental policy and biodiversity conservation planning priorities. Funding scarcity, legal limitations, and taxonomic uncertainty of Pontocaspian biota emerged as key contributing 
factors leading to the observed suboptimal conservation outcomes. With the current stakeholder landscape in Ukraine, it can be expected that improved taxonomic definitions of Pontocaspian species and better understanding/awareness, combined with increased research funding and more consistent conservation policy will quickly translate into increased conservation actions. The maintenance of the existing network in Ukraine is, however, a critically important precondition for such actions.

Responses to this article can be read online at: http://www.ecologyandsociety.org/issues/responses. $\mathrm{php} / 11575$

\section{Acknowledgments:}

We would like to thank the EU Innovative Training Network (ITN) Pontocaspian Biodiversity Rise and Demise (PRIDE) Program (grant agreement number: 642973 - PRIDE - H2020-MSCA$I T N-2014)$ for funding this research. We also thank the entire $W W F$ in Ukraine Team for their invaluable assistance and support. Furthermore, we thank Prof. Ivan Moysiyenko, from Kherson State University, and Sergei Ovechko, from NASU Kherson Hydrobiology Station for helping arrange meetings with stakeholders. We also thank all the interviewed stakeholders for finding time to meet and for providing honest and thorough answers to the survey questions. We would also like to acknowledge our colleagues from Naturalis Biodiversity Center: Nieke Knoben, for assistance in developing the questionnaire; Leon Marshall and Matteo Lattuada, for statistical advice and support; Thomas Edward Roberts and Martina de Freitas Prazeres, for the proofreading and for their helpful comments on earlier drafts of this paper; and Caroline van Impelen, for organizational support. Finally, we thank our reviewers who gave us invaluable comments that improved our work considerably.

\section{Data Availability Statement:}

The datalcode that support the findings of this study are available on request from the corresponding author, [A. G.]. The datalcode are not publicly available due to the sensitive information that could compromise the privacy of interviewees.

\section{LITERATURE CITED}

Abrahamson, E., and L. Rosenkopf. 1997. Social network effects on the extent of innovation diffusion: a computer simulation. Organization Science 8:289-309. https://doi.org/10.1287/orsc.8.3.289

Adger, W. N., K. Brown, and E. L. Tompkins. 2005. The political economy of cross-scale networks in resource co-management. Ecology and Society 10(2):9. https://doi.org/10.5751/ES-01465-100209

Anistratenko, V. V. 2009. Turricaspia lincta Milaschevitch, 1908. Page 290 in I. A. Akimov, editor. Red Data Book of Ukraine. Animal World. Global Consulting, Kiev, Ukraine.

Anistratenko, V. V., and O. Anistratenko. 2018. New finds of "Red Data Book" molluscs of the Ponto-Caspian biogeographic complex. Pages 19-20 in Materials to the fourth edition of the Red Data Book of Ukraine, Animal World. Kiev, Ukraine.
Barnes, M. L., J. Lynham, K. Kalberg, and P. Leung. 2016. Social networks and environmental outcomes. Proceedings of the National Academy of Sciences of the United States of America 113:6466-6471. https://doi.org/10.1073/pnas.1523245113

Binning, C., M. Young, and E. Cripps. 1999. Beyond roads, rates and rubbish: opportunities for local government to conserve native vegetation. Environment Australia, Biodiversity Group.

Bloesch, J., T. Jones, R. Reinartz, and B. Striebel. 2006. An action plan for the conservation of sturgeons (Acipenseridae) in the Danube River Basin. Österreichische Wasser-und Abfallwirtschaft 58:81-88. https://doi.org/10.1007/BF03165708

Bodin, Ö., and B. I. Crona. 2009. The role of social networks in natural resource governance: What relational patterns make a difference? Global Environmental Change 19:366-374. https://doi. org/10.1016/j.gloenvcha.2009.05.002

Bodin, Ö., B. Crona, and H. Ernstson. 2006. Social networks in natural resource management: What is there to learn from a structural perspective? Ecology and Society 11(2):r2. https://doi. org/10.5751/ES-01808-1102r02

Bogdan, R., and S. J. Taylor. 1975. Introduction to qualitative research methods. John Wiley \& Sons, New York.

Bradley, E. H., L. A. Curry, and K. J. Devers. 2007. Qualitative data analysis for health services research: developing taxonomy, themes, and theory. Health Services Research 42:1758-1772. https://doi.org/10.1111/j.1475-6773.2006.00684.x

Briggs, B. S. V. 2001. Linking ecological scales and institutional frameworks for landscape rehabilitation. Ecological Management \& Restoration 2:28-35. https://doi.org/10.1046/j.1442-8903.2001.00065. $\underline{\mathrm{X}}$

Cash, D. W., W. C. Clark, F. Alcock, N. M. Dickson, N. Eckley, D. H. Guston, J. Jäger, and R. B. Mitchell. 2003. Knowledge systems for sustainable development. Proceedings of the National Academy of Sciences of the United States of America 100:8086-8091. https://doi.org/10.1073/pnas.1231332100

Chang, H., J. Angelis, C. Nauwelaers, T. Posselt, and K. Schuch. 2017. Peer review of the Ukrainian Research and Innovation System. Horizon 2020 Policy Support Facility.

Cowling, R. M., and A. Wilhelm-Rechmann. 2007. Social assessment as a key to conservation success. Cambridge University Press New York, USA.

Crona, B., and Ö. Bodin. 2006. What you know is who you know? Communication patterns among resource users as a prerequisite for co-management. Ecology and Society 11(2):7. https://doi. org/10.5751/ES-01793-110207

Csardi, G., and T. Nepusz. 2006. The igraph software package for complex network research. InterJournal, Complex Systems 1695:1-9.

Cuttelod, A., M. Seddon, and E. Neubert. 2011. European Red List of non-marine molluscs. Publications Office of the European Union, Luxembourg.

Dumont, H., V. Mamaev, and Y. Zaitsev. 1999. Black Sea red data book. United Nations Office for Project Services. 
Durham, E., H. Baker, M. Smith, E. Moore, and V. Morgan. 2014. BiodivERsA stakeholder engagement handbook. BiddivERsA, Paris, France.

ECODIT LLC. 2017. Ukraine biodiversity analysis. United States Agency for International Development, Arlington, Virginia, USA.

Ernoul, L., and A. Wardell-Johnson. 2013. Governance in integrated coastal zone management: a social networks analysis of cross-scale collaboration. Environmental Conservation 40:231-240. https://doi.org/10.1017/S0376892913000106

Ernstson, H., S. Sörlin, and T. Elmqvist. 2008. Social movements and ecosystem services - the role of social network structure in protecting and managing urban green areas in Stockholm. Ecology and Society 13(2):39. https://doi.org/10.5751/ES-02589-130239

Fazey, I., A. C. Evely, M. S. Reed, L. C. Stringer, J. Kruijsen, P. C. White, A. Newsham, L. Jin, M. Cortazzi, J. Phillipson, et al. 2013. Knowledge exchange: a review and research agenda for environmental management. Environmental Conservation 40:19-36. https://doi.org/10.1017/S037689291200029X

Francis, R. A., and M. K. Goodman. 2010. Post-normal science and the art of nature conservation. Journal for Nature Conservation 18:89-105. https://doi.org/10.1016/j.jnc.2009.04.002

Freeman, L. C. 1978. Centrality in social networks conceptual clarification. Social Networks 1:215-239. https://doi.org/10.1016/0378-8733 (78)90021-7

Fuhse, J., and S. Mützel. 2011. Tackling connections, structure, and meaning in networks: quantitative and qualitative methods in sociological network research. Quality \& Quantity 45:1067-1089. https://doi.org/10.1007/s11135-011-9492-3

Giurca, A., and T. Metz. 2018. A social network analysis of Germany's wood-based bioeconomy: social capital and shared beliefs. Environmental Innovation and Societal Transitions 26:1-14. https://doi.org/10.1016/j.eist.2017.09.001

Glaser, B. G., A. L. Strauss, and E. Strutzel. 1967. The discovery of grounded theory: strategies for qualitative research. Aldine De Gruyter. Inc., New York, USA.

Grigorovich, I. A., T. W. Therriault, and H. J. MacIsaac. 2003. History of aquatic invertebrate invasions in the Caspian Sea. Pages 103-115 in J. Pedersen, editor. Marine bioinvasions: patterns, processes and perspectives. Springer. https://doi.org/10.1007/978-94-010-0169-4_9

Grilli, G., G. Garegnani, A. Poljanec, A. Ficko, D. Vettorato, I. De Meo, and A. Paletto. 2015. Stakeholder analysis in the biomass energy development based on the experts' opinions: the example of Triglav National Park in Slovenia. Folia Forestalia Polonica 57:173-186. https://doi.org/10.1515/ffp-2015-0017

Grinevetsky, S. R., I. S. Zonn, S. S. Zhiltsov, A. N. Kosarev, and A. G. Kostianoy. 2016. The Black Sea encyclopedia. Springer. https://doi.org/10.1007/978-3-642-55227-4

Hauck, J., C. Stein, E. Schiffer, and M. Vandewalle. 2015. Seeing the forest and the trees: facilitating participatory network planning in environmental governance. Global Environmental Change 35:400-410. https://doi.org/10.1016/j.gloenvcha.2015.09.022
Herz, A., L. Peters, and I. Truschkat. 2015. How to do qualitative strukturale analyse: the qualitative interpretation of network maps and narrative interviews. Forum: Qualitative Social Research 16(1):9.

Isaac, M. E. 2012. Agricultural information exchange and organizational ties: the effect of network topology on managing agrodiversity. Agricultural Systems 109:9-15. https://doi. org/10.1016/j.agsy.2012.01.011

Knoke, D., and J. H. Kuklinski. 1991. Network analysis: basic concepts. Pages 173-182 in G Thompson, J. Frances, R. Levacic, and J. Mitchell, editors. Markets, hierarchies and networks: the coordination of social life. Sage.

Kostianoy, A. G., and A. N. Kosarev, editors. 2005. The Caspian Sea environment. Springer Science \& Business Media. https://doi. org/10.1007/b138238

Krijgsman, W., A. Tesakov, T. Yanina, S. Lazarev, G. Danukalova, C. G. Van Baak, J. Agustí, M. Alçiçek, E. Aliyeva, D. Bista, et al. 2019. Quaternary time scales for the Pontocaspian domain: interbasinal connectivity and faunal evolution. Earth-Science Reviews 188:1-40. https://doi.org/10.1016/j.earscirev.2018.10.013

Lattuada, M., C. Albrecht, and T. Wilke. 2019. Differential impact of anthropogenic pressures on Caspian Sea ecoregions. Marine Pollution Bulletin 142:274-281. https://doi.org/10.1016/j. marpolbul.2019.03.046

Leavitt, H. J. 1951. Some effects of certain communication patterns on group performance. Journal of Abnormal and Social Psychology 46:38-50. https://doi.org/10.1037/h0057189

Lee, K. N. 1999. Appraising adaptive management. Conservation Ecology 3(2):3. https://doi.org/10.5751/ES-00131-030203

Markovsky, B., D. Willer, and T. Patton. 1988. Power relations in exchange networks. American Sociological Review 53:220-236. https://doi.org/10.2307/2095689

Marret, F., S. Leroy, F. Chalié, and F. Françoise. 2004. New organic-walled dinoflagellate cysts from recent sediments of Central Asian seas. Review of Palaeobotany and Palynology 129:1-20. https://doi.org/10.1016/j.revpalbo.2003.10.002

Mills, M., J. G. Álvarez-Romero, K. Vance-Borland, P. Cohen, R. L. Pressey, A. M. Guerrero, and H. Ernstson. 2014. Linking regional planning and local action: towards using social network analysis in systematic conservation planning. Biological Conservation 169:6-13. https://doi.org/10.1016/j.biocon.2013.10.015

Mizruchi, M. S., and J. Galaskiewicz. 1993. Networks of interorganizational relations. Sociological Methods \& Research 22:46-70. https://doi.org/10.1177/0049124193022001003

Munasypova-Motyash, I. A. 2009a. Hypanis laeviuscula (Milachevitch, 1916). Page 306 in I. A. Akimov, editor. Red Data Book of Ukraine. Animal World. Global Consulting, Kiev, Ukraine.

Munasypova-Motyash, I. A. 2009b. Hypanis plicata (Milashevitch, 1916). Page 307 in I. A. Akimov, editor. Red Data Book of Ukraine. Animal World. Global Consulting, Kiev, Ukraine.

Newman, L., and A. Dale. 2005. Network structure, diversity, and proactive resilience building: a response to Tompkins and Adger. Ecology and Society 10(1):r2. https://doi.org/10.5751/ES-01396-1001r02 
Newman, M. E. 2003. The structure and function of complex networks. SIAM Review 45:167-256.

Olsson, P., C. Folke, and T. Hahn. 2004. Social-ecological transformation for ecosystem management: the development of adaptive co-management of a wetland landscape in southern Sweden. Ecology and Society 9(4):2. https://doi.org/10.5751/ ES-00683-090402

Opsahl, T. 2009. Structure and evolution of weighted networks. Queen Mary, University of London.

Paletto, A., K. Hamunen, and I. De Meo. 2015. Social network analysis to support stakeholder analysis in participatory forest planning. Society \& Natural Resources 28:1108-1125. https://doi. org/10.1080/08941920.2015.1014592

Prell, C., K. Hubacek, and M. Reed. 2009. Stakeholder analysis and social network analysis in natural resource management. Society \& Natural Resources 22:501-518. https://doi. org/10.1080/08941920802199202

Pullin, A. S., and T. M. Knight. 2001. Effectiveness in conservation practice: pointers from medicine and public health. Conservation Biology 15:50-54. https://doi.org/10.1111/ j.1523-1739.2001.99499.x

Reed, M., I. Fazey, L. Stringer, C. Raymond, M. Akhtar-Schuster, G. Begni, H. Bigas, S. Brehm, J. Briggs, and R. Bryce. 2013. Knowledge management for land degradation monitoring and assessment: an analysis of contemporary thinking. Land Degradation \& Development 24:307-322. https://doi.org/10.1002/ $\underline{\text { ldr.1124 }}$

Reed, M. S., A. Graves, N. Dandy, H. Posthumus, K. Hubacek, J. Morris, C. Prell, C. H. Quinn, and L. C. Stringer. 2009. Who's in and why? A typology of stakeholder analysis methods for natural resource management. Journal of Environmental Management 90:1933-1949. https://doi.org/10.1016/j.jenvman.2009.01.001

Reed, M. S., L. C. Stringer, I. Fazey, A. Evely, and J. H. J. Kruijsen. 2014. Five principles for the practice of knowledge exchange in environmental management. Journal of Environmental Management 146:337-345. https://doi.org/10.1016/j.jenvman.2014.07.021

Ryan, G. W., and H. R. Bernard. 2003. Techniques to identify themes. Field Methods 15:85-109. https://doi.org/10.1177/15258$\underline{\text { 22X02239569 }}$

Salafsky, N., R. Margoluis, K. H. Redford, and J. G. Robinson. 2002. Improving the practice of conservation: a conceptual framework and research agenda for conservation science. Conservation Biology 16:1469-1479. https://doi.org/10.1046/ j.1523-1739.2002.01232.x

Sandström, A., and L. Carlsson. 2008. The performance of policy networks: the relation between network structure and network performance. Policy Studies Journal 36:497-524. https://doi. org/10.1111/j.1541-0072.2008.00281.X

Stork, D., and W. D. Richards. 1992. Nonrespondents in communication network studies: problems and possibilities. Group \& Organization Management 17:193-209. https://doi. org/10.1177/1059601192172006
Stringer, L. C., and A. J. Dougill. 2013. Channelling science into policy: enabling best practices from research on land degradation and sustainable land management in dryland Africa. Journal of Environmental Management 114:328-335. https://doi.org/10.1016/ j.jenvman.2012.10.025

van de Velde, S., E. L. Jorissen, T. A. Neubauer, S. Radan, A. B. Pavel, M. Stoica, C. G. Van Baak, A. Martínez Gándara, L. Popa, H. D. Stigter, et al. 2019. A conservation palaeobiological approach to assess faunal response of threatened biota under natural and anthropogenic environmental change. Biogeosciences 16:2423-2442. https://doi.org/10.5194/bg-16-2423-2019

Wasserman, S., and K. Faust. 1994. Social network analysis: methods and applications. Cambridge University Press.

Weimann, G. 1982. On the importance of marginality: one more step into the two-step flow of communication. American Sociological Review 47:764-773. https://doi.org/10.2307/2095212

Wesselingh, F. P., T. A. Neubauer, V. V. Anistratenko, M. V. Vinarski, T. Yanina, J. J. ter Poorten, P. Kijashko, C. Albrecht, O. Y. Anistratenko, A. D'Hont, et al. 2019. Mollusc species from the Pontocaspian region - an expert opinion list. ZooKeys 827:31-124. https://doi.org/10.3897/zookeys.827.31365

Yamaki, K. 2017. Applying social network analysis to stakeholder analysis in Japan's natural resource governance: two endangered species conservation activity cases. Journal of Forest Research 22:83-90. https://doi.org/10.1080/13416979.2017.1279706 
Appendix 1. Interview protocol, survey questions and missing SNA data.

\section{Interview protocol}

Network data was acquired through semi-structured, in-depth interviews with the heads or vice-heads of institutions using a questionnaire (see survey questions below). Qualitative data regarding the overall, tiefocused descriptions was collected using a general question: "Do you have professional acquaintance/links with [stakeholder organization named here from table 1]?" If the answer was positive, follow-up questions were asked, allowing interviewees to narrate the content of the interaction: "How would you describe your interaction with this stakeholder? What matters/topics do you discuss when you are in touch?" These questions were asked in general terms, without referring to Pontocaspian biodiversity. After the narrative, a specific question was asked addressing Pontocaspian biodiversity related information exchange: "Do you exchange scientific data, information, knowledge, opinion or advice regarding Pontocaspian biodiversity with this stakeholder organization?" In cases of short or unclear answers, the interviewees were asked to explain the link in more detail and provide examples of interaction. We were particularly interested in Pontocaspian biodiversity, so if the answer to this question was negative, we stopped asking regarding this particular stakeholder, and moved on asking about the next stakeholder organization from the list of identified 22 organizations. Subsequently, the interviewees were asked to rank the strength of the reported Pontocaspian biodiversity related interactions using a table of strength definitions developed as part of the questionnaire (Table A1.1). Once the Pontocaspian biodiversity related relational link was established, its perceived sufficiency was addressed through the question: "Do you consider your contact with this stakeholder sufficient or insufficient to achieve effective collaboration and information exchange?" In case of insufficiency, a follow-up question was asked: "If the contact is insufficient what is the reason you are not in contact more often?" Not all stakeholder institutions were easily reached or willing to answer the interview questions, resulting in some missing data. We used the imputation-by-reconstruction method (Stork and Richards 1992) to deal with missing data (see 'missing SNA data' section below for details). 


\section{Survey questions}

\section{Background}

1. Organization name

2. Name of the person interviewed

3. Position of the person interviewed

4. Location

5. Date

\section{Relationships for social network analysis (SNA)}

6. Do you have Professional acquaintance/links with [stakeholder organization named here from the list of selected 22 organizations]?

7. How would you describe your interaction with this stakeholder? What matters/topics do you discuss when you are in touch?

8. Do you exchange scientific data, information, knowledge, opinions or advice regarding the Pontocaspian biodiversity with this stakeholder organization?

9. From the table below, how strong would you classify your professional acquaintance/links with this stakeholder?

Table A1.1 Tie strength definitions.

\begin{tabular}{|ll|l|}
\hline Weight & Strength & Definition \\
$\mathbf{0}$ & Absent & We are never in contact with each other. \\
\hline $\mathbf{1}$ & Very weak & $\begin{array}{l}\text { We have been in contact at some point in the past and foresee } \\
\text { contact in the future. }\end{array}$ \\
\hline $\mathbf{2}$ & Weak & $\begin{array}{l}\text { We are in contact incidentally, e.g. if we have joint projects or if } \\
\text { we need specific knowledge, services, support or expertize from } \\
\text { each other. However, the rate of interaction is low and irregular. }\end{array}$ \\
\hline $\mathbf{3}$ & Strong & We are in contact regularly, on a monthly or quarterly basis. \\
\hline $\mathbf{4}$ & Very Strong & We are in contact very often, on a daily or weekly basis. \\
\hline
\end{tabular}

10. Do you consider your contact with this stakeholder sufficient or insufficient to achieve effective collaboration and information exchange?

10a. If the contact is insufficient what is the reason you are not in contact more often? 


\section{Missing SNA data}

Missing interview data complicates the social network analysis (Monge et al. 1983, Dean Jr and Brass 1985, Prell et al. 2009, Barnes et al. 2016). Ignoring missing values was demonstrated to have considerable negative effects on the structure of the network leading to significant loss of information (Huisman 2009). Huisman (2009) showed that in directed networks with small amounts of missing data (20-30\%), reconstruction provides more representative results than ignoring missing values. The reconstruction method assumes the link between a respondent and a non-respondent to be as reported by the respondent (Stork and Richards 1992). Two preconditions have to be met when using the imputationby-reconstruction method. Firstly, respondents shall be similar to non-respondents. Secondly, the description of the relational links provided by the respondents shall be reliable. The similarity of respondents and non-respondents shall be verified in two ways: in terms of individual level traits (e.g. legal status) and in terms of the number and strength of links they receive (Stork and Richards 1992). The reliability of the responses can be measured through the confirmation rate. Confirmation rate is the proportion of links described similarly by both stakeholders involved. If respondents and non-respondents are similar and the confirmation rate is high, it can be assumed that the respondent's description of the link accurately characterizes the relationship between respondent and non-respondent (Stork and Richards 1992). In this study, $82 \%$ of the links was gathered and $18 \%$ was missing, therefore below the $20 \%$ threshold. Out of the four institutions that could not be interviewed one is academic, one governmental, one non-governmental and one a protected area; therefore non-responding institutions are similar to responding institutions in terms of individual level traits. The confirmation rate was $88 \%$ and Chi-squared test revealed no significant differences in the distribution of the weights of received relationships between the respondents and non-respondents $(p$-value $=0.78$ ). Therefore, the imputation-by-reconstruction method was adopted.

\section{Literature cited}

Barnes, M. L., J. Lynham, K. Kalberg, and P. Leung. 2016. Social networks and environmental outcomes. Proceedings of the National Academy of Sciences 113:6466-6471.

Dean Jr, J. W., and D. J. Brass. 1985. Social interaction and the perception of job characteristics in an organization. Human Relations 38:571-582.

Huisman, M. 2009. Imputation of missing network data: some simple procedures. Journal of Social Structure 10:1-29.

Monge, P. R., J. A. Edwards, and K. K. Kirste. 1983. Determinants of communication network involvement: Connectedness and integration. Group \& Organization Studies 8:83-111.

Prell, C., K. Hubacek, and M. Reed. 2009. Stakeholder analysis and social network analysis in natural resource management. Society and Natural Resources 22:501-518.

Stork, D., and W. D. Richards. 1992. Nonrespondents in communication network studies: Problems and possibilities. Group \& Organization Management 17:193-209. 


\section{Appendix 2. Network findings.}

Table A2.1. Identified themes of stakeholder interactions and their descriptions. 'Frequency' reports the number of mentioning of identified themes by the interviewees. The numbers in brackets reflect how many times the theme was associated to strong vs. weak relational links.

\begin{tabular}{|c|c|c|c|}
\hline Category & Theme name & Theme description & $\begin{array}{l}\text { Frequency } \\
\text { (strong/weak) }\end{array}$ \\
\hline \multirow[t]{5}{*}{$\begin{array}{l}\text { Communication } \\
\text { relations }\end{array}$} & Opinions & $\begin{array}{l}\text { Exchange of opinions, consultations and recommendations on current work, plans and initiatives; exchange of project } \\
\text { management experiences. }\end{array}$ & $81(50 / 31)$ \\
\hline & $\begin{array}{l}\text { Ecological } \\
\text { data }\end{array}$ & $\begin{array}{l}\text { Exchange of data and knowledge directly or indirectly related to Pontocaspian communities. For example, data on } \\
\text { ecosystem functioning and dynamics to which Pontocaspian species are incidental; data on invasive species, which } \\
\text { potentially harm Pontocaspian species; data on species distribution and population genetics, which sometimes involve } \\
\text { Pontocaspian species; assistance with species identification. }\end{array}$ & $76(49 / 27)$ \\
\hline & $\begin{array}{l}\text { Environmental } \\
\text { data }\end{array}$ & $\begin{array}{l}\text { Exchange of information on the state of environment. For example, exchange of study results on the sea and fresh water } \\
\text { parameters, pollutants and water resources. }\end{array}$ & $33(22 / 11)$ \\
\hline & $\begin{array}{l}\text { Unspecified } \\
\text { content }\end{array}$ & $\begin{array}{l}\text { Exchange of Pontocaspian biodiversity related information reported by an interviewee without specifying the context or } \\
\text { the content of interaction. For example, 'if we need specific data we are in touch', 'sometimes our interests overlap'. }\end{array}$ & $25(11 / 14)$ \\
\hline & $\begin{array}{l}\text { Threatened } \\
\text { species data }\end{array}$ & Exchange of information on the state of threatened species, including the red list species; providing consultations. & $24(12 / 12)$ \\
\hline \multirow[t]{6}{*}{$\begin{array}{l}\text { Collaboration } \\
\text { relations }\end{array}$} & Research & $\begin{array}{l}\text { Joint fieldwork, lab work and publications, which sometimes involve Pontocaspian species and habitats. Hosting the } \\
\text { fieldworks and lab works, providing the necessary equipment and/or space for work and receiving the generated results. }\end{array}$ & $54(47 / 7)$ \\
\hline & $\begin{array}{l}\text { Conservation } \\
\text { planning }\end{array}$ & $\begin{array}{l}\text { Collaboration and joint conservation planning, e.g. agreeing on actions; developing and working in joint nature restoration } \\
\text { projects; providing scientific support for different conservation activities. }\end{array}$ & $36(22 / 14)$ \\
\hline & $\begin{array}{l}\text { Commercial } \\
\text { fishing }\end{array}$ & $\begin{array}{l}\text { Joint planning and regulation of matters related to commercial fishing. For example, rules, methods, mode of fishing, } \\
\text { limits, and quotes. }\end{array}$ & $15(9 / 6)$ \\
\hline & Expert groups & $\begin{array}{l}\text { Participation of experts in working group meetings and discussions, which are facilitated by the Ministry of Ecology to } \\
\text { solve the coastal lake, river and Black Sea related problems, which sometimes concern Pontocaspian habitats. }\end{array}$ & $7(4 / 3)$ \\
\hline & $\begin{array}{l}\text { Resource } \\
\text { management }\end{array}$ & Joint planning and agreeing on the procedures, limits and standards of use of different biological resources. & $6(2 / 4)$ \\
\hline & $\begin{array}{l}\text { Sturgeon } \\
\text { conservation }\end{array}$ & $\begin{array}{l}\text { Collaboration, planning and data exchange through the projects on charismatic Pontocaspian species, such as the } \\
\text { sturgeons. For example 'Life for Danube Sturgeons' (https://danube-sturgeons.org/). }\end{array}$ & $3(3 / 0)$ \\
\hline \multirow[t]{2}{*}{$\begin{array}{l}\text { Authority/power } \\
\text { relations }\end{array}$} & Directing action & $\begin{array}{l}\text { Giving directions of work and research, and asking for the generated study results or reports on outcomes, which } \\
\text { sometimes involve Pontocaspian species and habitats. }\end{array}$ & $10(5 / 5)$ \\
\hline & $\begin{array}{l}\text { Scientific } \\
\text { supervision }\end{array}$ & Developing and providing research standards and methodology. & $7(6 / 1)$ \\
\hline
\end{tabular}


Table A2.2. Number of mentioning of interaction themes by individual stakeholders. Values between brackets represent No. times the theme characterized the incoming ties and No. times the theme characterized the outgoing ties.

\begin{tabular}{|c|c|c|c|c|c|c|c|c|c|c|c|c|c|}
\hline & Commun & cation relat & ions & & & Collabor & tion relations & & & & & $\begin{array}{l}\text { Authority } \\
\text { relations }\end{array}$ & power \\
\hline Abbr. & Opinions & $\begin{array}{l}\text { Ecological } \\
\text { data }\end{array}$ & $\begin{array}{l}\text { Environmental } \\
\text { data }\end{array}$ & $\begin{array}{l}\text { Unspecified } \\
\text { content }\end{array}$ & $\begin{array}{l}\text { Threatened } \\
\text { species data }\end{array}$ & Research & $\begin{array}{l}\text { Conservation } \\
\text { planning }\end{array}$ & $\begin{array}{l}\text { Commercial } \\
\text { fishing }\end{array}$ & $\begin{array}{l}\text { Sturgeon } \\
\text { conservation }\end{array}$ & $\begin{array}{l}\text { Expert } \\
\text { groups }\end{array}$ & $\begin{array}{l}\text { Resource } \\
\text { management }\end{array}$ & $\begin{array}{l}\text { Directing } \\
\text { action }\end{array}$ & $\begin{array}{l}\text { Scientific } \\
\text { supervision }\end{array}$ \\
\hline MENR & $22(11,11)$ & $8(7,1)$ & $7(6,1)$ & $2(1,1)$ & $8(5,3)$ & $1(1,0)$ & $7(6,1)$ & $3(2,1)$ & $1(1,0)$ & $2(1,1)$ & $4(1,3)$ & $6(0,6)$ & 0 \\
\hline IMB & $20(7,13)$ & $21(8,13)$ & $1(1,0)$ & $2(2,0)$ & $4(2,2)$ & $10(3,7)$ & $6(5,1)$ & 0 & 0 & 0 & 0 & 0 & $4(0,4)$ \\
\hline BSBR & $9(5,4)$ & $15(6,9)$ & $6(3,3)$ & $6(3,3)$ & $2(1,1)$ & $9(5,4)$ & $3(1,2)$ & $2(1,1)$ & 0 & 0 & 0 & $1(1,0)$ & $1(1,0)$ \\
\hline DBR & $13(5,8)$ & $12(4,8)$ & $2(1,1)$ & $2(2,0)$ & $2(1,1)$ & $7(3,4)$ & $10(4,6)$ & $2(1,1)$ & $1(1,0)$ & 0 & 0 & $2(2,0)$ & $1(1,0)$ \\
\hline IZAN & $6(3,3)$ & $11(5,6)$ & 0 & $1(1,0)$ & $3(1,2)$ & $10(4,6)$ & $3(1,2)$ & 0 & 0 & 0 & 0 & 0 & $1(0,1)$ \\
\hline ONU & $6(3,3)$ & $14(5,9)$ & 0 & $1(1,0)$ & 0 & $13(9,4)$ & 0 & 0 & 0 & $2(1,1)$ & 0 & 0 & 0 \\
\hline IHB & $13(4,9)$ & $4(4,0)$ & 0 & $11(1,10)$ & 0 & $12(5,7)$ & $2(0,2)$ & 0 & 0 & $1(1,0)$ & 0 & 0 & $1(0,1)$ \\
\hline KHS & $4(2,2)$ & $11(3,8)$ & $5(1,4)$ & $1(1,0)$ & $3(0,3)$ & $9(4,5)$ & $2(1,1)$ & $2(1,1)$ & 0 & 0 & 0 & 0 & $1(1,0)$ \\
\hline YN & $4(2,2)$ & $7(3,4)$ & $12(3,9)$ & $1(1,0)$ & $9(2,7)$ & $6(5,1)$ & $1(0,1)$ & $11(3,8)$ & 0 & 0 & 0 & $1(1,0)$ & 0 \\
\hline US & $6(3,3)$ & $5(1,4)$ & $4(1,3)$ & $3(2,1)$ & $2(0,2)$ & $3(2,1)$ & $3(1,2)$ & $2(1,1)$ & 0 & $5(2,3)$ & 0 & $1(1,0)$ & $1(1,0)$ \\
\hline KSRP & $9(4,5)$ & $8(3,5)$ & $4(0,4)$ & $2(2,0)$ & 0 & $5(2,3)$ & $2(1,1)$ & 0 & 0 & 0 & 0 & $2(2,0)$ & $1(1,0)$ \\
\hline $\mathrm{KNU}$ & $7(3,4)$ & $3(2,1)$ & $1(0,1)$ & $4(2,2)$ & 0 & $8(4,4)$ & 0 & 0 & 0 & 0 & 0 & 0 & 0 \\
\hline CRS & $5(2,3)$ & $8(6,2)$ & $4(3,1)$ & $3(1,2)$ & $2(2,0)$ & 0 & $6(3,3)$ & 0 & 0 & 0 & 0 & 0 & 0 \\
\hline KSU & $2(2,0)$ & $2(2,0)$ & 0 & $2(1,1)$ & 0 & $8(3,5)$ & $3(0,3)$ & 0 & 0 & 0 & 0 & 0 & $1(0,1)$ \\
\hline OSRA & $8(6,2)$ & $4(4,0)$ & $1(1,0)$ & 0 & $3(3,0)$ & 0 & $5(3,2)$ & 0 & 0 & 0 & $4(2,2)$ & $1(0,1)$ & 0 \\
\hline LDNP & $3(3,0)$ & $3(1,2)$ & $3(2,1)$ & $3(1,2)$ & $1(1,0)$ & $4(2,2)$ & $3(1,2)$ & $1(1,0)$ & 0 & 0 & 0 & $2(2,0)$ & 0 \\
\hline MAPF & $1(1,0)$ & $3(2,1)$ & $5(3,2)$ & $1(1,0)$ & $2(1,1)$ & $1(1,0)$ & $1(1,0)$ & $5(3,2)$ & $1(1,0)$ & $2(1,1)$ & 0 & $1(0,1)$ & 0 \\
\hline MSRA & $5(4,1)$ & $7(4,3)$ & $6(3,3)$ & 0 & $1(1,0)$ & 0 & $3(1,2)$ & 0 & 0 & 0 & $3(2,1)$ & $1(0,1)$ & $1(1,0)$ \\
\hline NPBS & $8(3,5)$ & $2(2,0)$ & $2(2,0)$ & $4(2,2)$ & $1(1,0)$ & $2(1,1)$ & $1(0,1)$ & $1(1,0)$ & 0 & 0 & 0 & $1(1,0)$ & $1(1,0)$ \\
\hline WWF & $3(2,1)$ & $1(1,0)$ & $1(1,0)$ & 0 & $4(2,2)$ & 0 & $8(4,4)$ & $1(1,0)$ & $3(0,3)$ & 0 & 0 & 0 & 0 \\
\hline KSRA & $3(2,1)$ & $3(3,0)$ & $1(1,0)$ & 0 & $1(1,0)$ & 0 & $2(2,0)$ & 0 & 0 & 0 & $1(1,0)$ & $1(0,1)$ & 0 \\
\hline NECU & $5(4,1)$ & 0 & $1(1,0)$ & $1(0,1)$ & 0 & 0 & $1(1,0)$ & 0 & 0 & $2(1,1)$ & 0 & 0 & 0 \\
\hline
\end{tabular}


Table A2.3. Identified themes of insufficient interactions and their descriptions. 'Frequency' reports the number of times a theme was mentioned, with strength of representing links in parentheses.

\begin{tabular}{lll}
\hline Name & Description & $\begin{array}{l}\text { Frequency } \\
\text { (strong/weak) }\end{array}$ \\
\hline $\begin{array}{l}\text { Budget } \\
\text { constraints }\end{array}$ & $\begin{array}{l}\text { Organizations cannot achieve the desired levels of interaction due to the general } \\
\text { lack of funding for research and conservation initiatives; and/or due to the } \\
\text { unfavourable funding schemes, which restrict the participation of different types of } \\
\text { stakeholder organizations in a project. }\end{array}$ & $\begin{array}{l}18(13 / 5) \\
\text { Legal limitations }\end{array}$ \\
$\begin{array}{lll}\text { The desired levels of interaction cannot be achieved due to the lack of consistency } \\
\text { in conservation policy, which results from the contradicting national laws and } \\
\text { complicates collaboration and exchange of information. }\end{array}$ & $15(8 / 7)$ \\
$\begin{array}{l}\text { Lack of } \\
\text { interconnection } \\
\text { Employee } \\
\text { turnover }\end{array}$ & $\begin{array}{l}\text { The desired levels of interaction cannot be achieved because one of the stakeholders } \\
\text { abstains from having more contact. }\end{array}$ & $6(1 / 5)$ \\
\hline
\end{tabular}


Table A2.4. Stakeholder group relations. Values in brackets under 'Category' report the number of ties within or between stakeholder groups. An * indicates significant difference from random expectation at $5 \%$ level according to the null-model test.

\begin{tabular}{|c|c|c|c|c|}
\hline $\begin{array}{l}\text { Category } \\
\text { (No. ties) }\end{array}$ & $\begin{array}{l}\text { Density } \\
(\%)\end{array}$ & $\begin{array}{l}\text { No. ties } \\
\text { strong /weak }\end{array}$ & $\begin{array}{l}\text { Reasons for insufficient interaction } \\
\text { (No. mentioning) }\end{array}$ & Themes of interaction (No. mentioning) \\
\hline $\begin{array}{l}\mathrm{Pa}-\mathrm{Pa} \\
(14)\end{array}$ & 70 & $4 / 10$ & Budget constraints (1) & $\begin{array}{l}\text { Communication relations (Total 19) } \\
\text { Opinion (7) } \\
\text { Unspecified content (7) } \\
\text { Pontocaspian species data (4) } \\
\text { Environmental data (1) } \\
\text { Collaboration relations (Total 3) } \\
\text { Research (3) }\end{array}$ \\
\hline $\begin{array}{l}\text { Acad-Acad } \\
\text { (47) }\end{array}$ & $65^{*}$ & $35 / 12$ & Budget constraints (11) & $\begin{array}{l}\text { Communication relations (Total 55) } \\
\text { Pontocaspian species data (22) } \\
\text { Opinion (21) } \\
\text { Unspecified content (8) } \\
\text { Environmental data (3) } \\
\text { Threatened species data (1) } \\
\text { Collaboration relations (Total 36) } \\
\text { Research (28) } \\
\text { Conservation planning (3) } \\
\text { Expert groups (3) } \\
\text { Commercial fishing (2) } \\
\text { Authority/power relations (Total 2) } \\
\text { Scientific supervision (2) }\end{array}$ \\
\hline $\begin{array}{l}\text { Gov-Gov } \\
\text { (10) }\end{array}$ & 50 & $6 / 4$ & $\begin{array}{l}\text { Legal limitations (5) } \\
\text { Lack of interconnection (1) }\end{array}$ & $\begin{array}{l}\text { Communication relations (Total 8) } \\
\text { Opinion (4) } \\
\text { Environmental data (3) } \\
\text { Pontocaspian species data (1) } \\
\text { Collaboration relations (Total 8) } \\
\text { Resource management (6) } \\
\text { Commercial fishing (2) }\end{array}$ \\
\hline $\begin{array}{l}\text { NGO-NGO } \\
\text { (2) }\end{array}$ & 33 & $2 / 0$ & NA & $\begin{array}{l}\text { Communication relations (Total 1) } \\
\text { Opinion }(1) \\
\text { Collaboration relations (Total 2) } \\
\text { Conservation planning }(2)\end{array}$ \\
\hline $\begin{array}{l}\text { Acad-Pa } \\
(43)\end{array}$ & 24 & $29 / 14$ & $\begin{array}{l}\text { Budget constraints (5) } \\
\text { Legal limitations (4) } \\
\text { Lack of interconnection (2) }\end{array}$ & $\begin{array}{l}\text { Communication relations (Total 48) } \\
\text { Pontocaspian species data (19) } \\
\text { Opinion (12) } \\
\text { Environmental data (8) } \\
\text { Threatened species data (6) } \\
\text { Unspecified content (3) } \\
\text { Collaboration relations (Total 34) } \\
\text { Joint research (21) } \\
\text { Conservation planning (7) } \\
\text { Commercial fishing (6) } \\
\text { Authority/power relations (Total 4) } \\
\text { Scientific supervision (4) }\end{array}$ \\
\hline $\begin{array}{l}\text { Gov-NGO } \\
\text { (12) }\end{array}$ & 21 & $8 / 4$ & Employee turnover (2) & $\begin{array}{l}\text { Communication relations (Total 14) } \\
\text { Opinion (6) } \\
\text { Threatened species data (4) } \\
\text { Environmental data (2) } \\
\text { Pontocaspian species data (2) }\end{array}$ \\
\hline
\end{tabular}




\begin{tabular}{|c|c|c|c|c|}
\hline $\begin{array}{l}\text { Gov-Pa } \\
\text { (19) }\end{array}$ & 21 & $10 / 9$ & Lack of interconnection (3) & $\begin{array}{l}\text { Communication relations (Total 28) } \\
\text { Opinion (13) } \\
\text { Pontocaspian species data (9) } \\
\text { Environmental data (6) } \\
\text { Collaboration relations (Total 8) } \\
\text { Conservation planning (8) } \\
\text { Authority/power relations (Total 8) } \\
\text { Directing action (8) }\end{array}$ \\
\hline $\begin{array}{l}\text { Acad-Gov } \\
(28)\end{array}$ & 15 & $13 / 15$ & $\begin{array}{l}\text { Legal limitations (2) } \\
\text { Budget constraints (1) } \\
\text { Employee turnover (1) }\end{array}$ & $\begin{array}{l}\text { Communication relations (Total 44) } \\
\text { Opinion (12) } \\
\text { Pontocaspian species data (12) } \\
\text { Threatened species data (11) } \\
\text { Environmental data (6) } \\
\text { Unspecified content (3) } \\
\text { Collaboration relations (Total 13) } \\
\text { Conservation planning (5) } \\
\text { Commercial fishing (4) } \\
\text { Joint research (2) } \\
\text { Expert groups (2) } \\
\text { Authority/power relations (Total 3) } \\
\text { Directing action (2) } \\
\text { Scientific supervision (1) }\end{array}$ \\
\hline $\begin{array}{l}\text { NGO-Pa } \\
(6)\end{array}$ & 11 & $3 / 3$ & Legal limitations (2) & $\begin{array}{l}\text { Communication relations (Total 8) } \\
\text { Pontocaspian species data (4) } \\
\text { Opinion (3) } \\
\text { Environmental data (1) } \\
\text { Collaboration relations (Total 5) } \\
\text { Conservation planning (4) } \\
\text { Sturgeon conservation (1) }\end{array}$ \\
\hline $\begin{array}{l}\text { Acad-NGO } \\
\text { (10) }\end{array}$ & $8 *$ & $6 / 4$ & Legal limitations (2) & $\begin{array}{l}\text { Communication relations (Total 14) } \\
\text { Unspecified content (4) } \\
\text { Pontocaspian species data (3) } \\
\text { Environmental data (3) } \\
\text { Threatened species data (2) } \\
\text { Opinion (2) } \\
\text { Collaboration relations (Total 3) } \\
\text { Conservation planning (2) } \\
\text { Commercial fishing (1) }\end{array}$ \\
\hline
\end{tabular}

Collaboration relations (Total 9)

Conservation planning (5)

Expert groups (2)

Sturgeon conservation (2)

Communication relations (Total 28)

Opinion (13)

Pontocaspian species data (9)

Conservation planning (8)

Authority/power relations (Total 8)

Directing action (8)

Opinion (12)

Pontocaspian species data (12)

Threatened species data (11)

Environmental data (6)

pecified content (3)

Conservation planning (5)

Commercial fishing (4)

Joint research (2)

Expert groups (2)

Directing action (2)

Scientific supervision (1)

Communication relations (Total 8 )

Opinion (3)

Environmental data (1)

Conservation planning (4)

Sturgeon conservation (1)

Unspecified content (4)

Pontocaspian species data (3)

Environmental data (3)

Opinion (2)

Conservation planning (2)

Commercial fishing (1) 
Figure A2.1. Boxplot on number of themes representing a link and the strength of the link. Horizontal lines in the boxes represent the median values. Diamonds represent the mean number of the themes.

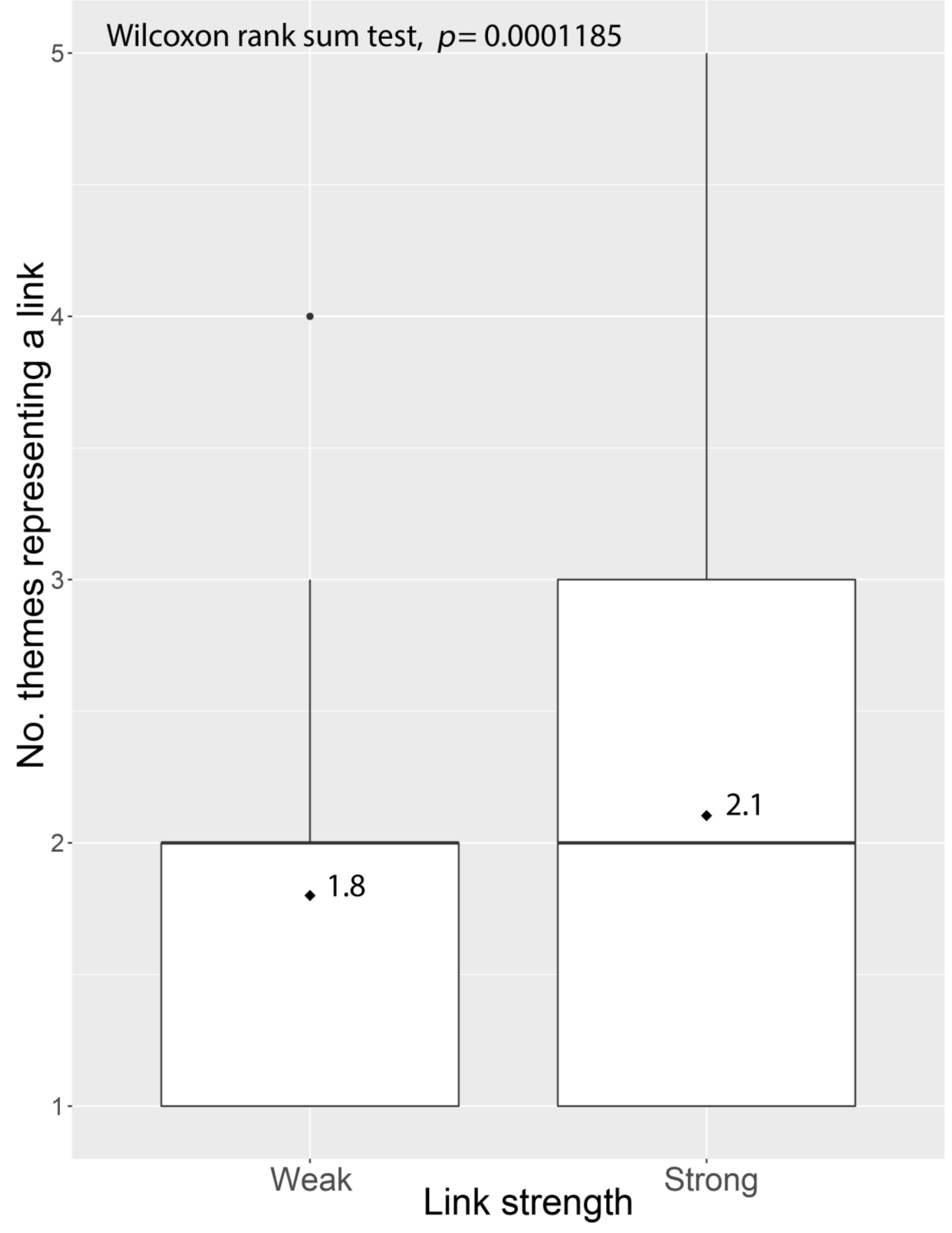




\section{Appendix 3. SNA term definitions.}

Betweenness centrality - a measure, developed to assess the extent to which a node is among other nodes in a network i.e. how many times a certain node connects the other two nodes that are not directly connected (Freeman 1978). Betweenness centrality takes the intermediary nodes into consideration and is calculated based on the shortest path among the nodes (Opsahl et al. 2010).

Broker - a node with high betweenness centrality (Freeman 1977) and/or low Burt's constraint score (Burt 1992, Lee 1999, Therriault et al. 2004), which both, receives but also sends many relational ties out to the other stakeholders (Wasserman and Faust 1994) and serves as a bridge between the disconnected or weakly connected stakeholders. Betweenness centrality locates the brokers with respect to all the other actors in the network. Burt's constraint however, is a local measure of brokerage based on the triadic closure principle. A triad is any three nodes in the network with any type of relationship (Davis and Leinhardt 1967). If the tie is absent between two neighboring nodes in a triad, then the triad is incomplete and has a structural hole in it (Burt 1992). A node connecting two disconnected nodes in an incomplete triad has a power to broker. Brokers have low Burt's constraint score, meaning that their behavior is not constrained by the other disconnected nodes in a triad (Burt 1992). High constraint on the actor means that it is involved in many complete triads and is constrained to act as broker.

Burt's constraint - a measure, developed to assess the extent to which an actor's behavior is constrained by the other actors in a network, based on a triadic closure principle. Actor can have a Burt's constraint value ranging from 0 , if it is involved in many incomplete triads, to 1 , if it is involved in many complete triads (Burt 1992). Lower the actor's Burt's constraint score, lesser its behavior is constrained by other nodes in the network.

Confirmation rate - proportion of relational links described similarly by both nodes involved (Stork and Richards 1992).

Degree centrality - the number of connections that a particular node has with all the other actors in a network (Freeman 1978). In a directed network, the degree of a node is measured through a combination of in-degree and out-degree values. The in-degree value of a node is the number of the actors that have an incoming link to it, and the out-degree value is the number of outgoing links from the node (Kleinberg 1998). In weighted networks node strength represents an extension of degree centrality to the sum of tie weights and integrates information about connectivity and the weights of links (Barrat et al. 2004, Newman 2004, Opsahl et al. 2008).

Directed network - a network, in which the edges have a direction, as such a message or resources are sent from a sender to a receiver (Shannon and Weaver 1949).

Edge - a relational link between actors, also known as arc or tie (Wasserman and Faust 1994).

Network centralization - a measure of the extent to which certain actors are more connected in the network than the others (Freeman et al. 1979, Wasserman and Faust 1994). A centralized network is one in which only one or few actors are having the majority of ties. Such a network has a high overall centralization score. If actors are not very different from each other in their degree of connectedness, the 
overall centralization score is low, so the network is decentralized. The network centralization index can be calculated based on 'degree centrality' scores of individual nodes, and indicates the relative dominance of single actors in the network (Freeman et al. 1979).

Network density - also referred to as the graph density, is a measure of the proportion of the relational ties that are actually present in a network. It is calculated by dividing the number of existing ties by all the possible ties in a network (Scott 1991). Density can have a value ranging from 0, if all the ties are absent, to 1, if all the possible ties are present (Scott 1991, Wasserman and Faust 1994).

Network homophily - a selective linking between actors based on specific attributes, such as the category of institution (Newman 2003). Stakeholders are more likely to form strong connections with similar stakeholders than with stakeholders from other categories as they have higher mutual understanding (Prell et al. 2009).

Node - representation of actor in a network, also referred to as a vertex or point (Wasserman and Faust 1994).

Node centrality - a measure of a particular actor's involvement in the network, represented through the degree and betweenness centralities. The more relational ties an actor has, and more times it connects the other nodes that are not directly connected, the more central it is.

Shortest distance - a minimum number of steps that the nodes are away from each other in a network. In weighted networks the tie weights shall be taken under consideration (Opsahl et al. 2010).

Sociogram - a two-dimensional picture showing relationships between the actors where the actors are represented by the nodes and the relationships between them are represented by the edges (Moreno 1953).

Theme - a recurrent unifying concept or a statement about the content/subject of the inquiry (Bradley et al. 2007).

Triad - any three nodes in a network with any type of relationship (Davis and Leinhardt 1967). A triad is complete if all three actors in it are connected to each other, and incomplete if a tie is absent between two neighboring nodes in it (Burt 1992).

Weighted network - a network in which the edges carry values that can be used as a measure of the strength of the relationship (Wasserman and Faust 1994).

\section{Literature cited}

Barrat, A., M. Barthélemy, and A. Vespignani. 2004. Weighted evolving networks: coupling topology and weight dynamics. Physical review letters 92:228701.

Bradley, E. H., L. A. Curry, and K. J. Devers. 2007. Qualitative data analysis for health services research: developing taxonomy, themes, and theory. Health services research 42:1758-1772. 
Burt, R. S. 1992. Structural Holes: The Social Structure of Competition. Harvard University Press, Cambridge, MA.

Davis, J. A., and S. Leinhardt. 1967. The structure of positive interpersonal relations in small groups.

Freeman, L. C. 1977. A set of measures of centrality based on betweenness. Sociometry:35-41.

Freeman, L. C. 1978. Centrality in social networks conceptual clarification. Social networks 1:215239.

Freeman, L. C., D. Roeder, and R. R. Mulholland. 1979. Centrality in social networks: II.

Experimental results. Social networks 2:119-141.

Kleinberg, J. M. 1998. Authoritative sources in a hyperlinked environment.in In Proceedings of the ACM-SIAM Symposium on Discrete Algorithms. Citeseer.

Lee, K. N. 1999. Appraising adaptive management. Conservation ecology 3.

Moreno, J. L. 1953. Who shall survive? Foundations of sociometry, group psychotherapy and sociodrama.

Newman, M. E. 2003. The structure and function of complex networks. SIAM review 45:167-256.

Newman, M. E. 2004. Analysis of weighted networks. Physical review E 70:056131.

Opsahl, T., F. Agneessens, and J. Skvoretz. 2010. Node centrality in weighted networks: Generalizing degree and shortest paths. Social networks 32:245-251.

Opsahl, T., V. Colizza, P. Panzarasa, and J. J. Ramasco. 2008. Prominence and control: the weighted rich-club effect. Physical review letters 101:168702.

Prell, C., K. Hubacek, and M. Reed. 2009. Stakeholder analysis and social network analysis in natural resource management. Society and Natural Resources 22:501-518.

Scott, J. 1991. Social network analysis: A handbook.

Shannon, C. E., and W. Weaver. 1949. The mathematical theory of communication. Urbana, IL: University of Illinois Press.

Stork, D., and W. D. Richards. 1992. Nonrespondents in communication network studies: Problems and possibilities. Group \& Organization Management 17:193-209.

Therriault, T. W., M. F. Docker, M. I. Orlova, D. D. Heath, and H. J. MacIsaac. 2004. Molecular resolution of the family Dreissenidae (Mollusca: Bivalvia) with emphasis on Ponto-Caspian species, including first report of Mytilopsis leucophaeata in the Black Sea basin. Molecular phylogenetics and evolution 30:479-489.

Wasserman, S., and K. Faust. 1994. Social network analysis: Methods and applications. Cambridge university press. 